\title{
Primary Versus Delayed Wound Closure Technique in Infected Laparotomy Wounds
}

\author{
Vijoy Singh ${ }^{1}$, Devang Kalathiya ${ }^{2}$, Shashikant $\mathrm{Shah}^{3}$ \\ ${ }^{1}$ Professor, Smt. B.K. Shah Medical Institute and Research Centre, Sumandeep Vidyapeeth Deemed to be university \\ (An Institution), Pipariya Vadodara, ${ }^{2}$ Resident, Smt. B.K. Shah Medical Institute and Research Centre, Sumandeep \\ Vidyapeeth Deemed to be university (An Institution), Pipariya Vadodara, ${ }^{3}$ Professor, Smt. B.K. Shah Medical \\ Institute and Research Centre, Sumandeep Vidyapeeth Deemed to be university (An Institution), Pipariya Vadodara
}

\begin{abstract}
Background: Contaminated laparotomy wounds have garnered little attention with high incidence of wound infections. Many techniques have been proposed for their management. The aim of this study is to compare the infection rates of laparotomy wounds using primary closure vs delayed closure in cases of peritonitis. The purpose is to identify a better wound closure technique for their management.

Method: This study included 105 patients, who were divided into two groups. Group A underwent primary closure and Group B underwent delayed closure, in which the wound was left open without suturing and saline irrigation was given to be sutured once the wound is clean. The wound infection was assessed using Southampton scoring system.

Results: A total of 54 patients, 30 (55.6\%) males and 24 (44.4\%) females were included. Group A, 27 patients with $55.6 \%$ males and $44.4 \%$ females. In Group B, 27 patients with $55.5 \%$ males and $44.4 \%$ females. The mean age in A was $39.4 \pm 11.8$ while that in B was $37.02 \pm 12.5$. Group A had an infection .rate of $77.4 \%$ whereas Group B had infection rate of only $34 \%$. The duration of hospital stay for Group B was 9.8 and for Group A was 11.7.
\end{abstract}

Conclusions: The delayed closure is an effective technique for wound closure in contaminated wounds, like perforation. Peritonitis, as it reduces wound infection rates and hospital stay.

Keywords: Laparotomy, closure, primary, delayed, infection.

\section{Introduction}

Exploratory laparotomy is one of the most common surgical procedures. This procedure is mostly done in emergency conditions like, DU perforation, gastric, ileal perforation, traumatic conditions etc. ${ }^{(1)}$

Surgical siteinfection(SSI) is clinically demonstrated as presence of pain over the surgical wound, which is

\section{Corresponding Author:}

Dr. Vijoy Singh

Professor, Smt. B.K. Shah Medical Institute and

Research Centre, Sumandeep Vidyapeeth Deemed to be University (An Institution), Pipariya Vadodara e-mail: drvijoyksingh@gmail.com

Ph: 9974005726 accompanied by erythema, local tenderness, induration or presence of purulent discharge at wound site. This is one of the most common complications of the laparotomy wounds following clean-contaminated and contaminated abdominal operations. ${ }^{(2)}$

Incidence of surgical wound infections can be minimized by different considerations such as use of surgical drapes, use of prophylactic antibiotics, adequate post-operative wound care in addition to a good surgical technique. $^{(3)}$

Despite the redundant use of antibiotics and choosing scrupulous surgical techniques, a surgical site infection continues to be a major problem in the vast majority of emergency surgeries conducted for perforation peritonitis. 
To have SSI and their complications like wound dehiscence, stitch granulomas or stitch abscesses is discouraging for the surgeon and a great discomfort for the patient. These complications increase the cost of treatment as well as prolong the hospital stay. In majority of emergency surgeries, in order to control and reduce the rate of wound. infections, various techniques of wound closure as well as preventive measures are being used but all efforts had uncertain outcomes. ${ }^{(4-5)}$

There are mainly two types of techniques for wound clore, which are primary and delayed wound closure. In primary wound closure, after the procedure, the wound edges are approximated intraoperatively with consideration to placement of a wound drain. Primary wound closure is routinely used as it is simple and no further procedures are required for later on. ${ }^{(6-8)}$

On the other hand, in delayed wound closure, skin is not approximated primarily, until thorough irrigation and dressing with saline for 3-5 days, following which it is closed. Regular dressings in delayed closure helps to decrease the anaerobic load at surgical sites but indirectly increases the exposure to staphylococci. ${ }^{(12,13)}$

Some surgeons favor delayed closure while a few of them advocate primary closure technique after a thorough lavaging with saline.

Objectives: The purpose of the present study was comparison of primary wound closure technique and delayed wound closure technique with respect to rate of wound infection and duration of hospital stay.

\section{Method}

This study was a prospective observational study on patients admitted in the surgery emergency department of Dhiraj Hospital, with perforation peritonitis, who underwent exploratory laparotomy during 2019-2020.

Patients with the diagnosis of perforated appendix, ileal perforation, colon perforation were chosen and distributed into two groups. In the study group, Group A, primary closure technique was used and in Group B, delayed closure technique was performed.

In group A, primary closure of musculo peritoneal and facial layer was done. Later thorough lavaging of the wound was done. A subcutaneous drain was inserted in some cases followed by skin closure. Sutures were removed on the 10th postoperative day.

However in delayed wound closure (Group B), after closure of musculo-peritoneal layers, subcutaneous and skin were packed with saline soaked gauze pieces. The wounds were dressed for $3-5$ days. Thereafter the skin was closed with tightening sutures. The sutures were removed after 10 days.

Both the groups were started empirically on third generation cephalosporin and metronidazole. The surgical site infections were assessed using Southampton scoring system on day 3 , day 5 , day 7 , day 10 . All patients were followed for early complications like wound infection, wound dehiscence or stitch abscess.

\section{Results}

This study was conducted among 54 patients. Study subjects were divided into two groups, with primary closure being done in 27 subjects and delayed wound closure in the remaining 27 subjects.

Among the primary wound closure group $11.1 \%$ had wound infection on post-op day 3 , whereas among those who underwent delayed closure, only $3.7 \%$ had wound infection on post-op day 3. (Table 1).

Table 1: Distribution of the study population based on type of wound closure and presence of infection on post-op day 3, day 5, day 7 and day 10 .

\begin{tabular}{|l|c|c|c|}
\hline Type of Closure & Present N(\%) & Absent N(\%) & Total N(\%) \\
\hline Infection on POD 3 & & & \\
Primary Closure & $3(11.1)$ & $24(88.9)$ & $27(100)$ \\
Delayed Closure & $1(3.7)$ & $26(96.3)$ & $27(100)$ \\
\hline Infection on POD 5 & & $12(44.5)$ & $27(100)$ \\
Primary Closure & $15(55.5)$ & $21(77.8)$ & $27(100)$ \\
Delayed Closure & $6(22.2)$ & \\
\hline
\end{tabular}




\begin{tabular}{|l|c|c|c|}
\hline Type of Closure & Present N(\%) & Absent N(\%) & Total N(\%) \\
\hline Infection on POD 7 & $12(44.4)$ & $15(45.6)$ & $27(100)$ \\
Primary Closure & $7(25.9)$ & $20(74.1)$ & $27(100)$ \\
Delayed Closure & & & \\
\hline Infection on POD 10 & $8(29.6)$ & $19(70.4)$ & $27(100)$ \\
Primary Closure & $2(7.4)$ & $25(92.6)$ & $27(100)$ \\
Delayed Closure & & & \\
\hline
\end{tabular}

Among the primary wound closure group $55.5 \%$ had wound infection on post-op day 5, whereas among those who underwent delayed primary closure only $22.2 \%$ had wound infection. (Table 1).

Among the primary wound closure group $44.4 \%$ had wound infection on post-op day 7 , whereas among those who underwent delayed primary closure only $25.9 \%$ had wound infection on post-op day 7 .

Among the primary wound closure group 29.6\% had wound infection on post-op day 10 , whereas among those who underwent delayed primary closure only $7.4 \%$ had wound infection on post-op day 10 .

Table 2: Distribution of study population based on type of wound closure and overall infection rate

\begin{tabular}{|l|c|c|c|}
\hline Type of Wound Closure & Infection Present & Infection Absent & Total \\
\hline Primary Closure & $21(77.7 \%)$ & $6(22.3 \%)$ & 27 \\
\hline Delayed Closure & $12(44.4 \%)$ & $15(55.6 \%)$ & 27 \\
\hline
\end{tabular}

On exploring the overall infection rates in both groups, among the primary wound closure group $77.7 \%$ had wound infection and in delayed primary closure only $44.4 \%$ had wound infection. (Table 2)

Table 3: Distribution of study population having complications

\begin{tabular}{|l|c|c|c|}
\hline Type of Wound Closure & Wound Dehiscence & Stitch Abscess & Stitch Sinus \\
\hline Primary Closure & $6(22 \%)$ & $2(7.4 \%)$ & $1(3.7 \%)$ \\
\hline Delayed Closure & $1(3.7 \%)$ & 0 & 0 \\
\hline
\end{tabular}

On observing the wound dehiscence rates, primary closure had $22 \%$ cases, while in delayed closure $3.7 \%$ had wound dehiscence. Stitch abscess was found in $7.4 \%$ in primary closure while delayed closure had none.

Table 4: Mean duration of hospital stay based of closure type

\begin{tabular}{|l|c|}
\hline Closure Type & Duration (Days) \\
\hline Primary Closure & 11.7 \\
\hline Secondary Closure & 9.8 \\
\hline
\end{tabular}

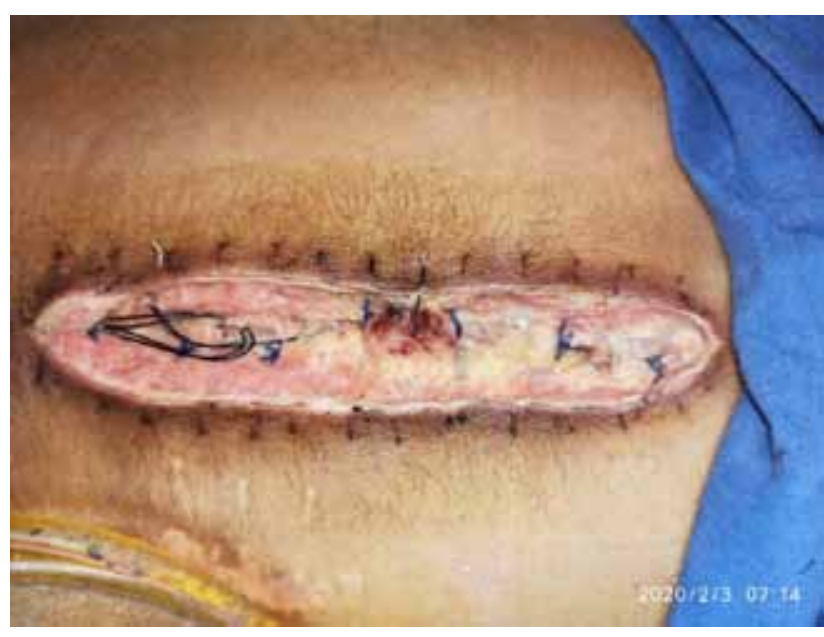

Figure 1: Showing wound dehiscence post laparotomy in a case of perforation peritoitis 


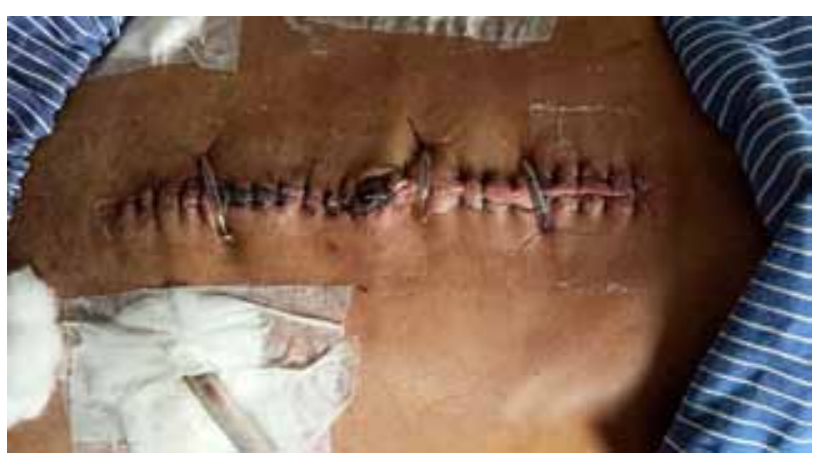

Figure 2: Showing wound after delayed closure of laparotomy wound

\section{Discussion}

The current study was conducted among 54 patients who underwent exploratory laparotomy for perforation peritonitis, of whom 27 subjects had undergone primary wound closure and 27 underwent delayed wound closure.

The two groups were similar with respect to age and gender as well as indication for surgery. There was a slight male preponderance $(55.6 \%)$ in the study population.

The overall infection rate in the study population was $61.1 \%$. On comparing primary and delayed wound closure with respect to wound infection rates, it was seen that there was a significantly higher rate of wound infection after primary closure as compared to delayed closure (77.7\% vs $44.4 \%$ ) (Table 3 ).

This difference in the rate of wound infections between the two may be explained by the fact that, in the patients undergoing primary closure, the microorganisms are trapped in the subcutaneous tissue. This space has poor drainage causing collection of surgical debris which provide an excellent medium, allowing bacteria to grow and multiply rapidly leading to increased incidence of wound infection. On the other hand delayed wound closure prevents the formation of seroma and anaerobic environment in the wound, thus avoiding bacterial proliferation.

Another explanation in favour of delayed wound closure is that, leaving the wounds open, as in delayed wound closure, prevent infection as repeated dressing change accomplishes adequate drainage..$^{14,15}$

Thus the current study strengthens the view that delayed wound closure is associated with significantly less wound infection rates.

\section{Conclusion}

There was significant reduction in rates of wound infection after delayed closure of contaminated wounds. Hence, the strategy of delayed wound closure seems to be better than primary closure in decreasing the rate of SSI.

Ethical Clearance: Taken from sumandeep vidyapeeth institutional ethics committee

\section{Source of Funding: Self}

\section{Conflict of Interest: Nil.}

\section{References}

1. Mahesh C B, Shivakumar S, Suresh BS, Chidanand SP, Vishwanath Y.A prospective study of surgical site infection in a teaching hospital. Journal of clinical and diagnostic research 2010 October; 4:3114-9.

2. Kore S, Vyavaharkar M, Akolekar R,Toke A, Ambiye V. J Postgrad Med 2000; 46:26-28.

3. Hedrick TL, Sawyer RG, Hennessy SA, Turrentine FE, Friel CM. Can We Define Surgical Site Infection in Colorectal Surgery?. Surgical Infect 2014;15(4):372-6.

4. Haridas M, Malangoni MA. Predictive factors for surgical site infection in general surge. Surg. 2008;144(4):496-503.

5. Greisman HC. Wound management and medical organization in the Civil War. Surg Clinics North Am. 1984;64(4):625-38.

4. Fukuda H, Morikane K, Kuroki M, Kawai S, Hayashi K, Ieiri Y, et al. Impact of surgical site infections after open and laparoscopic colon and rectal surgeries on postoperative resource consumption. Infect. 2012;40(6):649-59.

5. Kusachi S, Kashimura N, Konishi T, Shimizu J, Kusunoki M, Oka M, et al. Length of stay and costfor surgical site infection after abdominal and cardiac surgery in Japanese hospitals: multicentersurveillance. Surg Infect (Larchmt). 2012;13(4):257-65.

6. Andersson AE, Bergh I, Karlsson J, Nilsson K. Patients' experiences of acquiring a deep surgicalsite infection: an interview study. Am J Infect Control. 2010;38(9):711-7. 
7. Mangram AJ, Horan TC, Pearson ML, Silver LC, Jarvis WR. Guideline for prevention of surgical site infection, 1999. Am J Infect Control. 1999;27(2):97-134.

8. Poole D, Chieregato A, Langer M, Viaggi B Cingolani E, Malacarne P, et al. Systematic review of theliterature and evidence-based recommendations for antibiotic prophylaxis in trauma: results froman Italian consensus of experts. 2014;9(11).

9. Murtaza B, Khan AN, Sharif MA, Malik IB, Mahmood A. Modified midline abdominal woundclosure technique in complicated/high risk laparotomies. J Coll Physicians Surg Pak. 2010;20(1):37-41.

10. Gurjar V, Halvadia BM, Bharaney RP, Ajwani V, Shah SM, Rai S, et al. Study of two techniques for midline laparotomy fascial wound closure. Indian J Surg. 2014;76(2):91-4.

11. Van't Riet M, Steyerberg EW, Nellensteyn J, Bonjer HJ, Jeekel J. Meta-analysis of techniques for closure of midline abdominal incisions. $\mathrm{Br} \mathrm{J}$ Surg. 2002;89(11):1350-6.
12. Khan KI, Mahmood S, Akmal M, Waqas A. Comparison of rate of surgical wound infection, length of hospital stay and patient convenience in complicated appendicitis between primary closure and delayed primary closure. J Pak Med Assoc. 2012;62(6):596-8.

13. Duttaroy DD, Jitendra J, Duttaroy B, Bansal U, Dhameja P, Patel G, et al. Management strategy fordirty abdominal incisions: primary or delayed primary closure. A randomized trial. Surg Infect(Larchmt). 2009;10(2):129-36.

14. Siribumrungwong B, Noorit P, Wilasrusmee C, Thakkinstian A. A systematic review of meta analysis of randomised controlled trials of delayed primary wound closure contaminated abdominal wounds. World J Emerg Surg. 2014;9(1):49.

15. Nasib G, Shah SI, Bashir EA. Laparotomy for peritonitis: primary or delayed primary closure? J Ayub Med Coll Abbottabad Jamc. 2015; 27(3):543-5. 